\title{
On the prediction of channel heads in a complex alpine terrain using gridded elevation data
}

\author{
Stefano Orlandini, ${ }^{1}$ Paolo Tarolli, ${ }^{2}$ Giovanni Moretti, ${ }^{1}$ and Giancarlo Dalla Fontana ${ }^{2}$ \\ Received 11 June 2010; revised 19 November 2010; accepted 8 December 2010; published 23 February 2011.
}

[1] Threshold conditions for channel initiation are evaluated by using gridded elevation data derived from a lidar survey, a reliable algorithm for the determination of surface flow paths, and field observations of channel heads for a study area located in the eastern Italian Alps. These threshold conditions are determined by considering the channel heads observed across a portion of the study area and computing the related values of (1) drainage area $A$, (2) area-slope function $A S^{2}$, with $S$ being the local slope, and (3) Strahler order $\omega^{*}$ of surface flow paths extracted from gridded elevation data. Attention is focused on the dependence of the obtained threshold values on the size of grid cells involved and on the ability of the identified threshold conditions to provide reliable predictions of channel heads across the entire study area. The results indicate that the threshold values of $A, A S^{2}$, and $\omega^{*}$ are all significantly dependent on grid cell size, and the uncertainty in the determination of threshold values of $\omega^{*}$ is significantly smaller than that affecting the determination of threshold values of $A$ and $A S^{2}$. The comparison between predicted and observed channel heads indicates that the considered methods display variable reliability and sensitivity over different drainage basins and grid cell sizes, with a general tendency to predict more channel heads than can be observed in the field. Acceptable predictions are normally obtained where channel heads are formed essentially by surface runoff. More comprehensive methods seem, however, to be needed to predict channel heads affected by groundwater seeping upward.

Citation: Orlandini, S., P. Tarolli, G. Moretti, and G. Dalla Fontana (2011), On the prediction of channel heads in a complex alpine terrain using gridded elevation data, Water Resour. Res., 47, W02538, doi:10.1029/2010WR009648.

\section{Introduction}

[2] The identification of the factors determining the location and density of stream channels and valleys in drainage basins is a perennial concern in geomorphology, with implications for understanding of drainage basin origin, scale and morphology, basin hydrology, and effects of natural and man-induced process changes [Dunne and Leopold, 1978, p. 694]. As pointed out by Howard [1994], some confusion has resulted from a failure to distinguish between the "channel" (or "stream") network, defined by channels with well-defined banks and sources, and the "valley" (or "drainage") network, which is defined on the basis of basin morphometry. The factors determining the locations of channel heads can be modeled by considering fluvial and/or landsliding processes singly or in combination [Montgomery and Dietrich, 1988, 1989, 1992; Dietrich and Dunne, 1993]. In contrast, valley networks result from the cumulative action of erosional processes over the longer timescales commensurate with the evolution of the large-scale topography [Kirkby, 1993]. A network and its associated drainage density can be defined for either or both the channel and

\footnotetext{
${ }^{1}$ Department of Mechanical and Civil Engineering, University of Modena and Reggio Emilia, Modena, Italy.

${ }^{2}$ Department of Land and Agroforest Environments, University of Padova, Padua, Italy.
}

Copyright 2011 by the American Geophysical Union. 0043-1397/11/2010WR009648 valley system, but they are not equivalent. Attention is focused in this study on the determination of the channel network in grid-based digital elevation models.

[3] The channel network is the pattern of tributaries and master streams in a drainage basin as delineated on a planimetric map [Leopold et al., 1964, p. 131]. In theory, the network includes all the minor rills which are definite watercourses, even including all the ephemeral channels in the farthest headwaters. In practice, the direct survey of all channels is normally a prohibitive task, and headward limits of channels are often drawn to fit a personalized esthetic rather than some well-defined hydrological or geomorphological principle [Leopold, 1994, p. 228]. There is, therefore, a need for predictive methods incorporating the essential features of basin hydrology and geomorphology which may be used to provide detailed representations of channel networks based on a practicable number of field observations. More specifically, these predictive methods are needed to represent the channel network in grid-based digital elevation models, which are largely used in detailed small-scale catchment models [e.g., Orlandini and Rosso, 1998; Camporese et al., 2010] and also in modern largescale catchment models, where grid-based representations of headwaters are coupled with vector-based representations of the river network provided by hydrographic data sets (e.g., C. H. David et al., River network routing on the NHDPlus dataset, submitted to Journal of Hydrometeorology, 2011.

[4] Although many studies addressing the prediction of channel heads have been presented in the literature [e.g., 
Tribe, 1992; Montgomery and Foufoula-Georgiou, 1993; Ijjasz-Vasquez and Bras, 1995; Pilotti et al., 1996; Istanbulluoglu et al., 2002; Kirkby et al., 2003; Hancock and Evans, 2005; McNamara et al., 2006], the problem of positioning channel heads in grid-based digital elevation models remains a challenge in computational hydrology and geomorphology [e.g., Martz and Garbrecht, 1995; Imaizumi et al., 2010]. Most of the investigations carried out in the last two decades were limited by the lack of high-resolution digital elevation model data and field studies necessary to map in detail the precise location of channel heads [Dietrich et al., 1993; Montgomery and Foufoula-Georgiou, 1993; Ijjasz-Vasquez and Bras, 1995]. High-resolution data are now widely available as a reflection of advances in the lidar (light detection and ranging) technology, and accurate flow direction methods have been developed to fully exploit these data [e.g., Tarboton, 1997; Orlandini et al., 2003; Seibert and McGlynn, 2007]. Technological advances in surveying and computation have recently been used to identify the morphology of channels directly from digital elevation model data [e.g., Lashermes et al., 2007; Tarolli and Dalla Fontana, 2009; Pirotti and Tarolli, 2010; Passalacqua et al., 2010a, 2010b]. Methods aiming to predict channel heads from nonlocal drainage basin features remain, however, relevant to investigate the essential mechanisms governing channel head formation and to position channel heads in distributed catchment models having limited grid resolution as a result of computational constraints.

[5] Nonlocal methods for the prediction of channel heads in grid-based digital elevation models can be defined by considering different threshold conditions for channel initiation. O'Callaghan and Mark [1984] and Tarboton et al. [1988] defined channel networks on a digital elevation model as those pixels that have an accumulated drainage area $A$ greater than some "threshold support area." Montgomery and Dietrich [1988] proposed to use a threshold on the monomial (product of nonnegative integer powers of variables) function $A S^{2}$ of the drainage area $A$ and the local slope $S$. The channel initiation function $\beta A^{m} S^{n}$, where $\beta$ is a coefficient and $m$ and $n$ are real exponents, has been used by other researchers [e.g., Willgoose et al., 1991]. IjjaszVasquez and Bras [1995] noted that the related channel initiation criterion can be equivalently stated by using the power function $A S^{k}$, with $k=n / m$ being a real exponent, and proposed a procedure for estimating $k$ from the average local slope versus drainage area scatterplot. Channel initiation functions $A S^{2}$ and $A S^{k}$ are conceptually similar, and the former does not require any parameter to be estimated. $A S^{2}$ is, therefore, considered in preference to $A S^{k}$ in the present study. Peckham [1995] introduced a method based on Horton's [1945] and Strahler's [1952, 1957] classification of surface flow paths extracted from digital elevation data, in which exterior links having order $\omega^{*}$ smaller than or equal to a given threshold are pruned.

[6] In the present study, these methods are evaluated by using accurate field observations of channel heads collected in the eastern Italian Alps [Pirotti and Tarolli, 2010], gridded elevation data obtained from lidar surveys [Cavalli et al., 2008; Tarolli and Dalla Fontana, 2009], and stateof-the-art methods for the delineation of drainage basins and surface flow paths [Orlandini et al., 2003; Orlandini and Moretti, 2009a, 2009b]. Threshold values of $A, A S^{2}$, and $\omega^{*}$ are computed by considering the channel heads observed across a portion of the study area. Attention is then focused on critical issues that still remain to be explored, such as the dependence of threshold values on the size of grid cells involved and the ability of the identified threshold conditions to provide reliable predictions of channel heads across drainage basins having different morphology.

\section{Study Area}

[7] The study area is located in the Dolomites, a section of the eastern Italian Alps. The centroid of this study area has latitude $46^{\circ} 27^{\prime} 51.90^{\prime \prime} \mathrm{N}$ and longitude $12^{\circ} 6^{\prime} 16.37^{\prime \prime} \mathrm{E}$ As shown in Figure 1, elevation ranges from 1935 to $2589 \mathrm{~m}$ above sea level (asl), with an average of $2244 \mathrm{~m}$ asl. The average terrain slope is $46 \%$. The vegetation covers $97 \%$ of the area and consists of high-altitude grassland (91\%) and sporadic tall forest $(6 \%)$. The remaining $3 \%$ of the area is unvegetated talus deposits. The geological formations include sandstones with calcareous-marly rock outcrops Moraines and scree deposits, and landslide accumulations are also present. Soil thickness varies between $0.2 \mathrm{~m}$ on topographic spurs and $1.5 \mathrm{~m}$ on topographic hollows [Borga et al., 2002; Tarolli et al., 2008]. The soil thickness was measured at 20 different locations across the study area. At each location, three soil thickness replicates 1-2 m apart were collected by driving a $180 \mathrm{~cm}$ long sharpened steel rod graduated at $5 \mathrm{~cm}$ intervals vertically into the ground using a pounder until refusal. The area has a typical alpine climate with a mean annual rainfall of about $1100 \mathrm{~mm}$. Precipitation occurs mainly as snowfall from November to April. During summer, storm events and long dry spells are common. Runoff is dominated by snowmelt in May and June, but summer and early autumn floods represent an important contribution to the flow regime. Although an extensive field campaign for the measurement of runoff has not been carried out so far, different surface runoff production mechanisms have been observed to occur across the study area in response to rainfall and snowmelt events. Saturation excess (Dunne) runoff occurs especially along valleys and channels in response to long, low-intensity events, whereas infiltration excess (Horton) runoff occurs across the whole drainage basins in response to short, high-intensity events. No artificial structures are present in the headwaters of the selected study area, where channels develop their morphology in response to loads of water and sediments imposed on them, reflecting ultimately the natural interaction between climate and geology.

[8] Three drainage basins, denominated DB1, DB2, and DB3 in Figure 1, are considered. DB1 is the Rio di Col Duro drainage basin, DB2 has no name, and DB3 is the Rio d'Ambrizzola drainage basin. All three drainage basins are subbasins of the Rio Cordon drainage basin. The areas of DB1, DB2, and DB3 are equal to $0.455,0.081$, and 0.708 $\mathrm{km}^{2}$, respectively. Mean elevations are equal to 2199,2132 , and $2285 \mathrm{~m}$ asl, respectively. Mean slopes are equal to $49 \%$, $57 \%$, and $42 \%$, respectively. As shown in Figure 1, the channels observed in the three drainage basins can be classified as colluvial (photograph a), bedrock (photograph b), and alluvial (photograph c) channels. The colluvial incisions are small headwater channels, exhibiting a weak or 


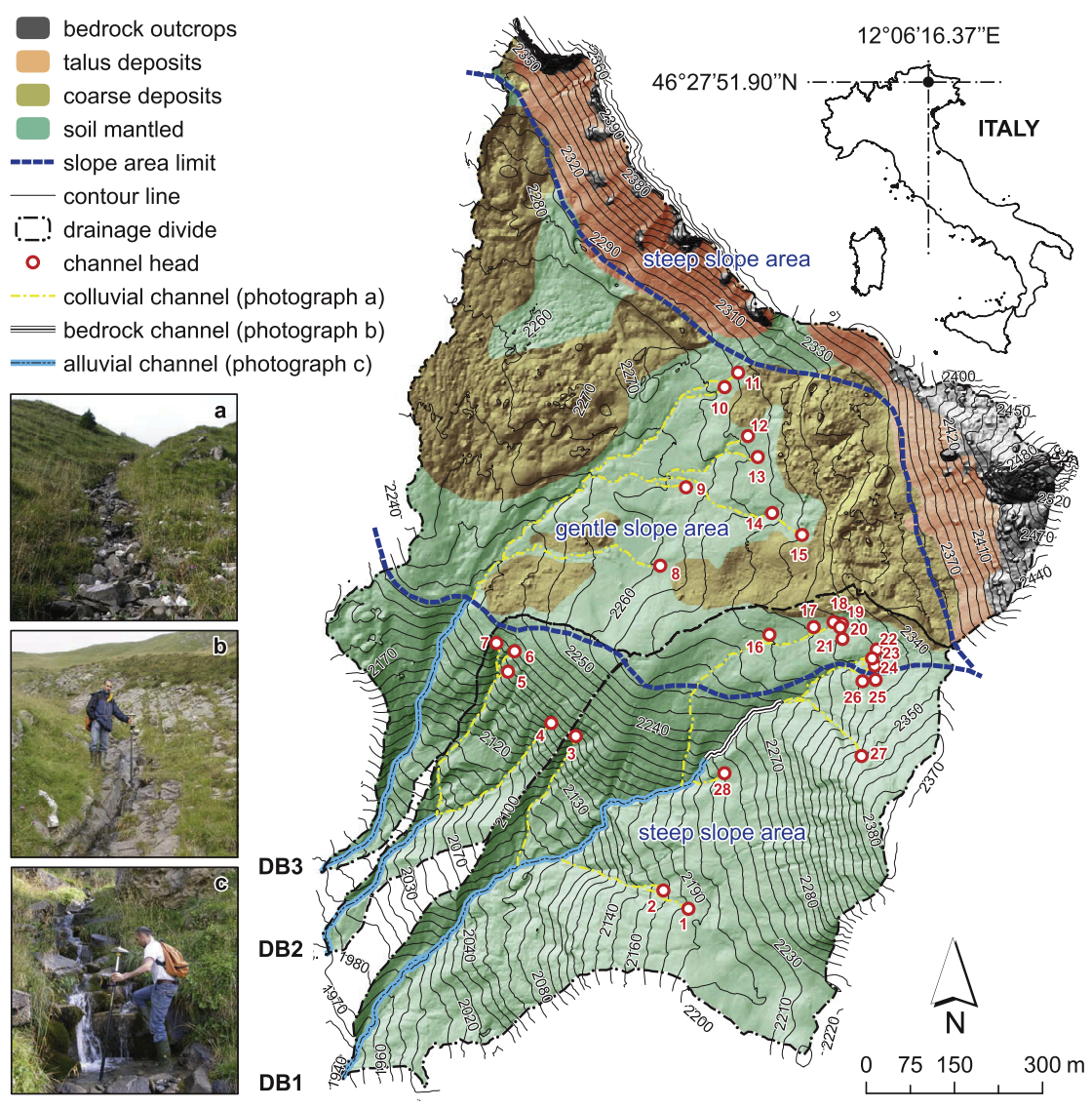

Figure 1. Topographic map of the study area showing observed channel heads and related channels. Three drainage basins (DB), denominated DB1, DB2, and DB3, are considered. DB1 is the Rio di Col Duro drainage basin, DB2 has no name, and DB3 is the Rio d'Ambrizzola drainage basin. Land surface properties and channel types are shown in the map and in photographs $\mathrm{a}, \mathrm{b}$, and c below the legend.

ephemeral transport capacity [Montgomery and Buffington, 1997]. They can be considered as the elementary component of the hydrologic network, defining channel initiation [Montgomery and Dietrich, 1989]. The alluvial channel network is dominated by erosional and depositional processes controlled mainly by local slope changes, where the sediment forming the channel bed can be transported and organized during floods. Alluvial channels display bed morphologies such as cascades and step pool, which are typical of steep mountainous channel reaches characterized by high transport capacity [Vianello and D'Agostino, 2007].

[9] Several surveys, including a lidar survey, were conducted in the study area during the past few years. Field surveys were carried out in September and October 2008. The area was systematically walked along all channels and surface flow paths up to the drainage basin divide. Twentyseven channel heads were mapped with an accuracy of a few centimeters using a differential global positioning system (DGPS). The channel head or first-order stream was defined as the point at which nonconfined divergent flows on the hillslope converge to a drainage line with welldefined banks and flow paths, which is the upstream limit of concentrated flow [Dietrich and Dunne, 1993]. The width of surveyed channels at the bankfull stage was found to range from 1 to $5 \mathrm{~m}$. The lidar survey was carried out, during snow-free conditions, in October 2006. Lidar data and high-resolution aerial photographs were acquired from a helicopter using an airborne laser terrain mapper (ALTM) 3100 OPTECH and Rollei H20 Digital camera flying at an average altitude of $1000 \mathrm{~m}$ above ground level. The survey design point density was specified to be greater than 5 points $/ \mathrm{m}^{2}$, recording up to four returns, including first and last. The mean absolute vertical accuracy, evaluated by a direct comparison between lidar and ground DGPS elevation points, was estimated to be less than $0.3 \mathrm{~m}$ [Pirotti and Tarolli, 2010]. Lidar point measurements were filtered into returns from vegetation and bare ground using the Terras$\mathrm{can}^{\mathrm{TM}}$ software classification routines and algorithms. The lidar bare ground data set was used to generate an accurate $1 \mathrm{~m}$ resolution digital elevation model. The natural neighbor technique was used for this operation [Sibson, 1981]. The $1 \mathrm{~m}$ gridded elevation data were then regridded on 3 , $5,10,20$, and $30 \mathrm{~m}$ grid cell resolution by using the mean aggregation function in order to obtain coarser digital elevation models. While $1 \mathrm{~m}$ gridded elevation data generated from the lidar bare ground data set using the natural neighbor technique were found to provide extracted surface flow paths that compare favorably with those observed in the 
field, the mean aggregation function was found to ensure an high degree of consistency between surface flow paths extracted from gridded elevation data having different resolutions.

\section{Identification of Channel Heads}

[10] Surface flow paths are determined in this study by using the D8-LTD (eight flow directions, least transverse deviation) single flow direction algorithm [Orlandini et al., 2003; Orlandini and Moretti, 2009a, 2009b]. The D8-LTD method performs a path-based analysis in which the deviations between steepest and possible flow directions are accumulated along the path and not just evaluated at the local scale as done in the original D8 method proposed by O'Callaghan and Mark [1984]. In the D8-LTD method, transverse deviations are used in preference to angular deviations since they were found to provide the most accurate determinations of surface flow paths [Orlandini et al., 2003; Orlandini and Moretti, 2009b]. Surface flow paths are assumed in this study to occur along the slope lines, defined by Maxwell [1870] as those lines that intersect contour lines at right angles. Under this assumption, single flow direction algorithms are preferred to multiple flow direction algorithms such as those proposed by Quinn et al. [1991], Tarboton [1997], and Seibert and McGlynn [2007]. Orlandini and Moretti [2009a] show that the D8-LTD method provides a sound description of surface flow paths and drainage areas. With respect to the simpler D8 method, the D8-LTD method solves the problem of aligned surface flow paths along slopes and therefore provides an accurate determination of surface flow paths and related classifications in the small areas supporting the channel heads.

[11] Three methods for the automated identification and prediction of channel heads from gridded elevation data are evaluated. Each of these methods defines a threshold condition for channel initiation and assumes that channels originate where threshold exceedences occur. Thresholds are given in terms of (1) drainage area $A$ as proposed by O'Callaghan and Mark [1984] and Tarboton et al. [1988], (2) monomial function of the drainage area $A$ and local slope $S$ of the kind $A S^{2}$ as suggested by Montgomery and Dietrich [1992], and (3) Strahler order $\omega^{*}$ of surface flow paths extracted from gridded elevation data as proposed by Peckham [1995]. The drainage area $A$ at a given cell is computed by accumulating local contributions along the upslope drainage system. The slope $S$ at a given cell is evaluated along the flow direction toward its downslope neighbor, and it is conventionally assumed to be positive downward. A two-step procedure is used to determine the channel network using method 3. In the first step, Strahler classification is applied to all surface flow paths of the digital elevation model, including those generated at the source cells. A surface flow path order $\omega^{*}$ is assigned to each link between a source and a junction or between junctions. In the second step, surface flow paths having an order less than or equal to a given threshold $\omega_{t}^{*}$ are pruned. The remaining surface flow paths are assumed to provide the predicted channel network. Channel orders $\omega$ in the obtained channel network are computed as

$$
\omega=\omega^{*}-\omega_{t}^{*} .
$$

[12] Numerical experiments are carried out to investigate the ability of the considered methods to identify and reproduce observed channel heads. Special attention is paid to the dependence of threshold conditions for channel initiation on the size of grid cells involved. Relationships expressing the variation of threshold variables for channel initiation with the grid cell size are determined by considering the channel heads observed within DB1 and are then applied to the DB2 and DB3. Gridded elevation data having cell sizes $h$ equal to $1,3,5,10,20$, and $30 \mathrm{~m}$ are considered. For each of the 16 channel heads observed within DB1 and for each grid cell size $h$, threshold drainage area $A_{t}$, area slope function $\left(A S^{2}\right)_{t}$, and Strahler order $\omega_{t}^{*}$ are determined by considering surface flow paths obtained from the D8-LTD flow direction algorithm. For any given grid cell size, mean and standard deviation of the related threshold variables are assumed to provide the best values and the average uncertainty connected to the estimation of these best values, respectively [Taylor, 1997, p. 101]. Accordingly, these values are represented in Figure 2 as data points and uncertainty bars, respectively. The bands formed by connecting the end points of uncertainty bars are shaded in Figure 2 to highlight the uncertainty with which threshold conditions for channel initiation are determined from field observations and gridded elevation data.

[13] Weighted least squares fitting is applied to determine the relationships expressing the variations of threshold variables with grid cell size [Taylor, 1997, p. 198]. Linear models of the kind $y=a+b x$ are used to describe the variation of threshold variables $A_{t}$ and $\left(A S^{2}\right)_{t}$ with grid cell size $h$, where $y$ represents the variable $A_{t}$ or $\left(A S^{2}\right)_{t}, x$ represents the variable $h$, and $a$ and $b$ are parameters. In addition, a linear model of the kind $y=a+b x$ is also used to describe the simple power function relationship $\omega_{t}^{*}=\alpha h^{\beta}$ between the threshold variable $\omega_{t}^{*}$ and the grid cell size $h$, where $\alpha$ and $\beta$ are parameters, $y=\log \omega_{t}^{*}, a=\log \alpha, b=\beta$, and $x=$ $\log h$ (logarithms are to base 10 throughout the paper). Weighted least squares fitting is applied to the six data points $\left(x_{i}, y_{i}\right)(i=1, \ldots, 6)$, which have different, known uncertainties $\sigma_{i}$. The values of $\sigma_{i}(i=1, \ldots, 6)$ are computed by using the standard deviations of threshold variables $A_{t},\left(A S^{2}\right)_{t}$, and $\omega_{t}^{*}$, namely, $\sigma_{A_{t}}, \sigma_{\left(A S^{2}\right)}$, and $\sigma_{\omega_{t}^{*}}$, as $\sigma_{i}=\sigma_{A_{t}}, \sigma_{i}=\sigma_{\left(A S^{2}\right)_{t}}$, and $\sigma_{i}=\left[\log \left(\omega_{t}^{*}+\sigma_{\omega_{t}^{*}}\right)-\log \left(\omega_{t}^{*}-\right.\right.$ $\left.\left.\sigma_{\omega_{t}^{*}}\right)\right] / 2$, respectively [Orlandini et al., 2006]. The weight associated with each data point $\left(x_{i}, y_{i}\right)(i=1, \ldots, 6)$ is then determined as $w_{i}=1 / \sigma_{i}^{2}$. It is remarked here that uncertainties $\sigma_{i}$ in the determination of threshold variables $y_{i}$ are computed from observed channel heads and terrain attributes extracted directly from gridded elevation data. As such, they incorporate the contributions to total uncertainty due to errors in the positioning of observed channel heads, in gridded elevation data, and in terrain analysis methods, as well as the inherent inaccuracy of the considered channel initiation conditions. These different sources of uncertainty can be evaluated separately by applying the uncertainty analysis methods described, for instance, by Orlandini et al. [2006]. This analysis is beyond the scope of the present study.

[14] Predictive relationships for threshold variables are shown in Figure 2 and reported in Table 1 along with the related correlation coefficients $R$, coefficients of determination $R^{2}$, and $p$ values [Taylor, 1997, p. 218]. The results 

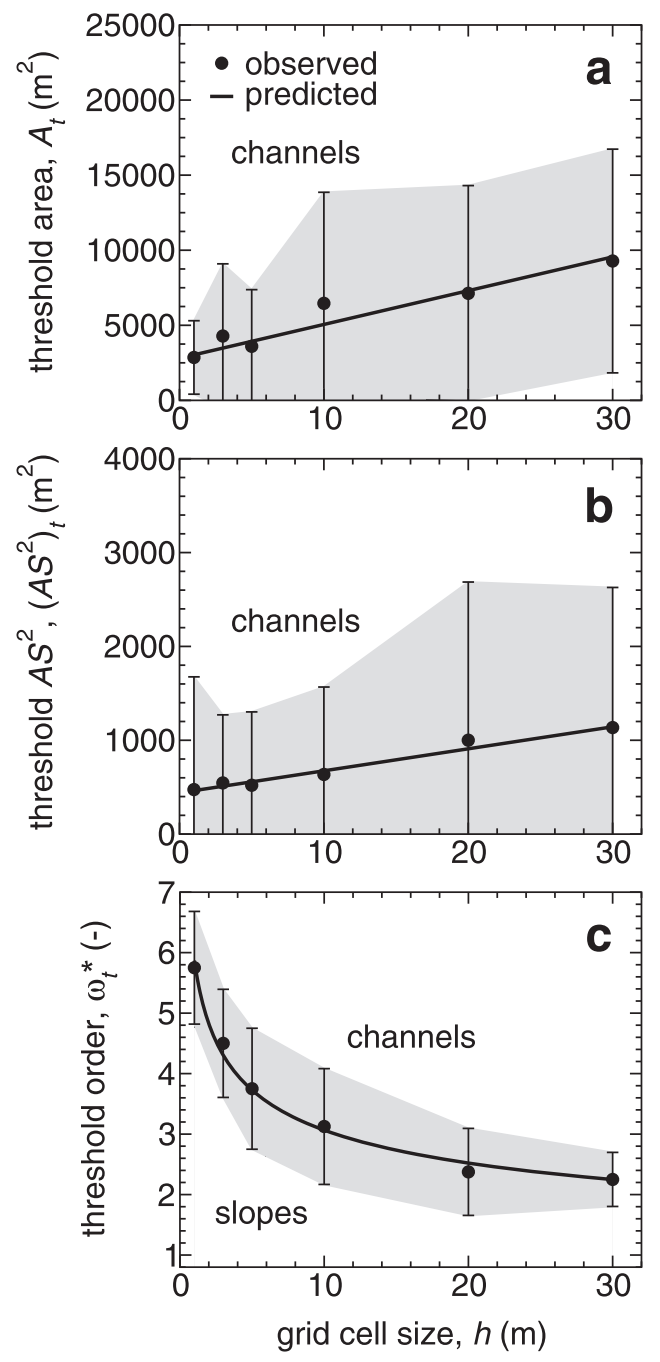

Figure 2. Observed and predicted variations of threshold variables for channel initiation with grid cell size. Means (data points) and standard deviations (uncertainty bars) of threshold values of (a) drainage area $A$, (b) area-slope function $A S^{2}$, and (c) Strahler order of surface flow paths extracted from gridded elevation data $\omega^{*}$, computed on the channel heads observed in DB1, are provided for each grid cell size $h$. Predictive relationships are obtained by weighted least squares fitting.

shown in Figures $2 \mathrm{a}$ and $2 \mathrm{~b}$ reveal that threshold values $A_{t}$ and $\left(A S^{2}\right)_{t}$ increase as the grid cell size $h$ increases. The linear models reported in Table 1 display correlation coefficients $R$ equal to 0.961 and 0.978 , coefficients of determination $R^{2}$ equal to 0.924 and 0.956 , and $p$ values equal to

Table 1. Relationships Between Threshold Variables for Channel Initiation and Grid Cell Size

\begin{tabular}{lccc}
\hline Relationship $^{\mathrm{a}}$ & $R$ & $R^{2}$ & $p$ \\
\hline$A_{t}=2806.61+224.90 h$ & 0.961 & 0.924 & 0.0023 \\
$\left(A S^{2}\right)_{t}=439.71+23.46 h$ & 0.978 & 0.956 & 0.0007 \\
$\omega_{t}^{*}=5.869 h^{-0.282}$ & -0.997 & 0.994 & $<0.0001$ \\
\hline
\end{tabular}

${ }^{\mathrm{a}} A_{t}\left(\mathrm{~m}^{2}\right)$, threshold drainage area; $\left(A S^{2}\right)_{t}\left(\mathrm{~m}^{2}\right)$, threshold $A S^{2}$ function; $\omega_{t}^{*}$ (dimensionless), threshold Strahler order of surface flow paths; $h(\mathrm{~m})$, grid cell size.
0.0023 and 0.0007 , respectively. As shown in Figure 2c, the threshold value $\omega_{t}^{*}$ is found to decrease as the grid cell size $h$ increases. The power function relationship reported in Table 1 , transformed logarithmically, displays a correlation coefficient $R$ equal to -0.997 , a coefficient of determination $R^{2}$ equal to 0.994 , and a $p$ value less than 0.0001 . By denoting correlations as "highly significant" if $p<0.01$, all the correlations reported in Figure 2 and Table 1 can be considered to be highly significant [e.g., Taylor, 1997, p. 218].

[15] The significance of the computed threshold variables $A_{t},\left(A S^{2}\right)_{t}$, and $\omega_{t}^{*}$ must be qualified by the accuracy with which surface flow paths are determined and terrain attributes are computed. Orlandini and Moretti [2009a] compared surface flow paths and catchment areas obtained from several methods based on gridded elevation data using a detailed contour and flow line network [Moretti and Orlandini, 2008] as a reference. The D8-LTD method was found to be equally or more accurate than other existing methods, and the relationship

$$
h \leq 0.15 A^{0.4}
$$

was found to provide the upper bound of grid cell size $h$ that should be considered in order to ensure type 2 relative errors $E_{2}$ in the delineations of drainage basins having area $A$ are less than $10 \%$. In the case of DB1 considered in Figure 2, headwaters have an area of the order of $4000 \mathrm{~m}^{2}$ (Figure $2 \mathrm{a}$ with $h=1 \mathrm{~m}$ ), and gridded elevation data with cell size not exceeding $4.1 \mathrm{~m}$ should be considered in order to meet the requirement expressed by (2). Errors made by applying the D8-LTD method to grid data with resolutions of $1,3,5,10,20$, and $30 \mathrm{~m}$ are equal to $2 \%, 7 \%, 11 \%, 23 \%$, $46 \%$, and $68 \%$, respectively, as given by $E_{2} \simeq 0.63 \mathrm{~h} / \mathrm{A}^{0.4}$ with $A=4000 \mathrm{~m}^{2}$ [Orlandini and Moretti, 2009a, p. 12]. Nonetheless, in order to evaluate circumstances commonly found in geomorphological and hydrological applications, grid cell sizes greater than $4.1 \mathrm{~m}$ are considered. Values of $h$ exceeding $30 \mathrm{~m}$ are not considered owing to the accuracy issue reported above and also to the fact that $A_{t}$ and $\omega_{t}^{*}$ clearly tend to $h^{2}$ and 1 , respectively, as $h$ increases.

[16] The results reported in Figure 2 and Table 1 provide indications of the ability of the methods to identify threshold values for channel initiation that are invariant over the considered channel heads and vary with the size of the grid cells involved in a predictable manner. These indications are expressed by standard deviations represented by uncertainty bars and by the coefficients of determination of predictive relationships for threshold variables, respectively. However, these capabilities do not necessarily imply the ability of methods to predict accurately the channel heads. In fact, well-identified threshold conditions can provide predictions of channel heads in locations where these heads do not actually occur. In other words, as better explained in sections 5 and 6, small uncertainty bars and good fits of observed data indicate that a method is sensitive (i.e., it does not produce false negatives), but it does not necessarily ensure that the model is reliable (i.e., it does not produce false positives). In addition, the predictive capabilities of the considered relationships need to be evaluated for test cases that are not used for their determination. A more comprehensive evaluation of the considered methods is therefore reported in sections 4 and 5. 


\section{Prediction of Channel Heads}

[17] The values of threshold variables for channel initiation given by the relationships reported in Figure 2 and Table 1 have been used to extract the channel heads from gridded elevation data having variable resolution. All drainage basins DB1, DB2, and DB3 are considered in this phase, as shown in Figures 3 and 4. Figure 3 shows the channel networks obtained from the elevation data of DB1 at the resolutions of $3 \mathrm{~m}$ (Figures $3 \mathrm{a}, 3 \mathrm{c}$, and $3 \mathrm{e}$ ) and $30 \mathrm{~m}$ (Figures $3 \mathrm{~b}, 3 \mathrm{~d}$, and $3 \mathrm{f}$ ) using the values of $A_{t}$ (Figures $3 \mathrm{a}$ and $3 \mathrm{~b}),\left(A S^{2}\right)_{t}$ (Figures $3 \mathrm{c}$ and $3 \mathrm{~d}$ ), and $\omega_{t}^{*}$ (Figures $3 \mathrm{e}$ and $3 \mathrm{f})$ given by the relationships reported in Figure 2 and Table 1 , namely, $A_{t}=3481.3 \mathrm{~m}^{2},\left(A S^{2}\right)_{t}=510.1 \mathrm{~m}^{2}$, and $\omega_{t}^{*}=4$ for $h=3 \mathrm{~m}$ and $A_{t}=9553.5 \mathrm{~m}^{2},\left(A S^{2}\right)_{t}=1143.5 \mathrm{~m}^{2}$, and $\omega_{t}^{*}=2$ for $h=30 \mathrm{~m}$. In these cases, the most satisfactory channel heads are those obtained by considering the

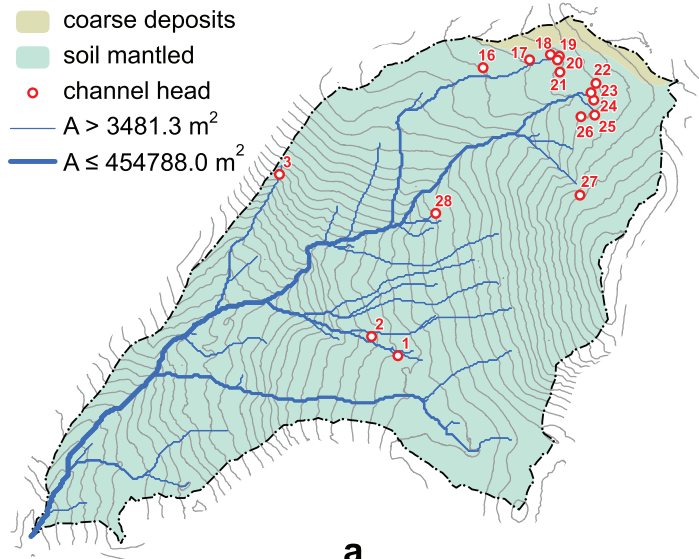

a

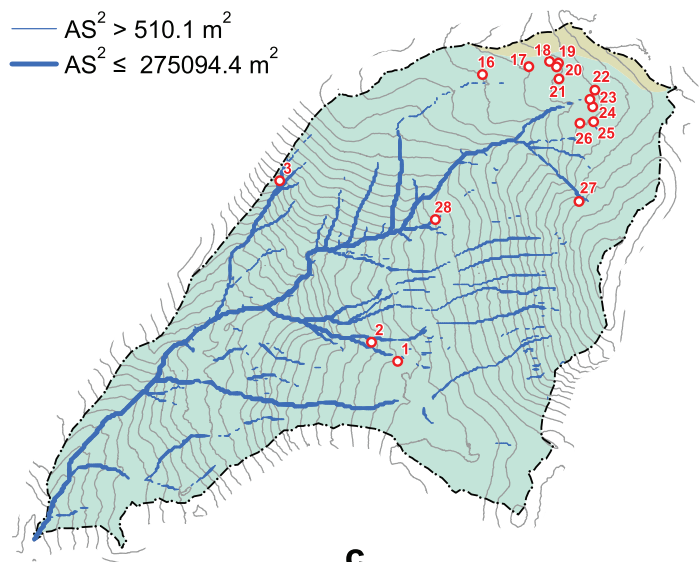

C

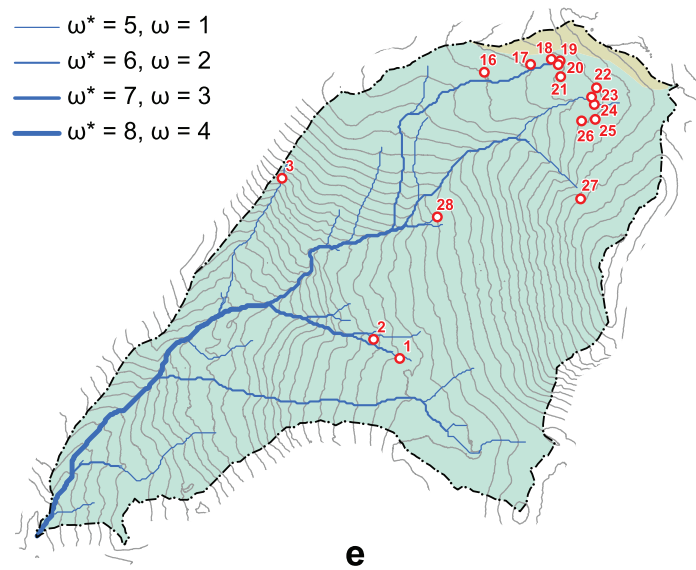

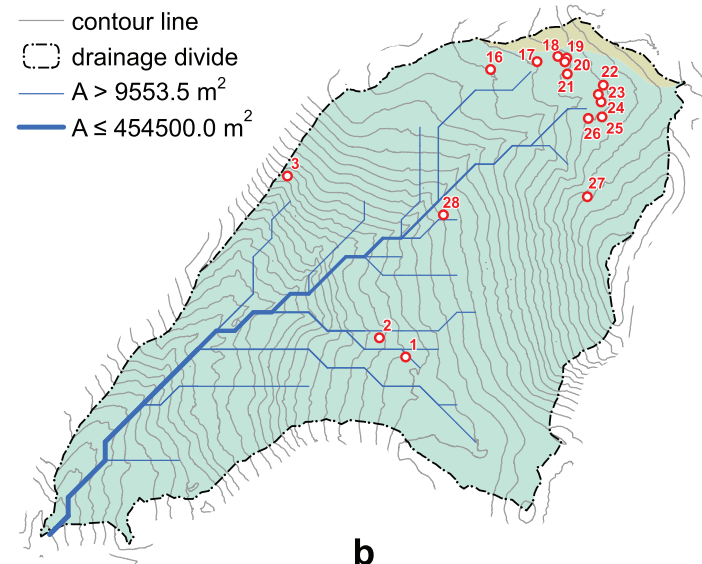

b
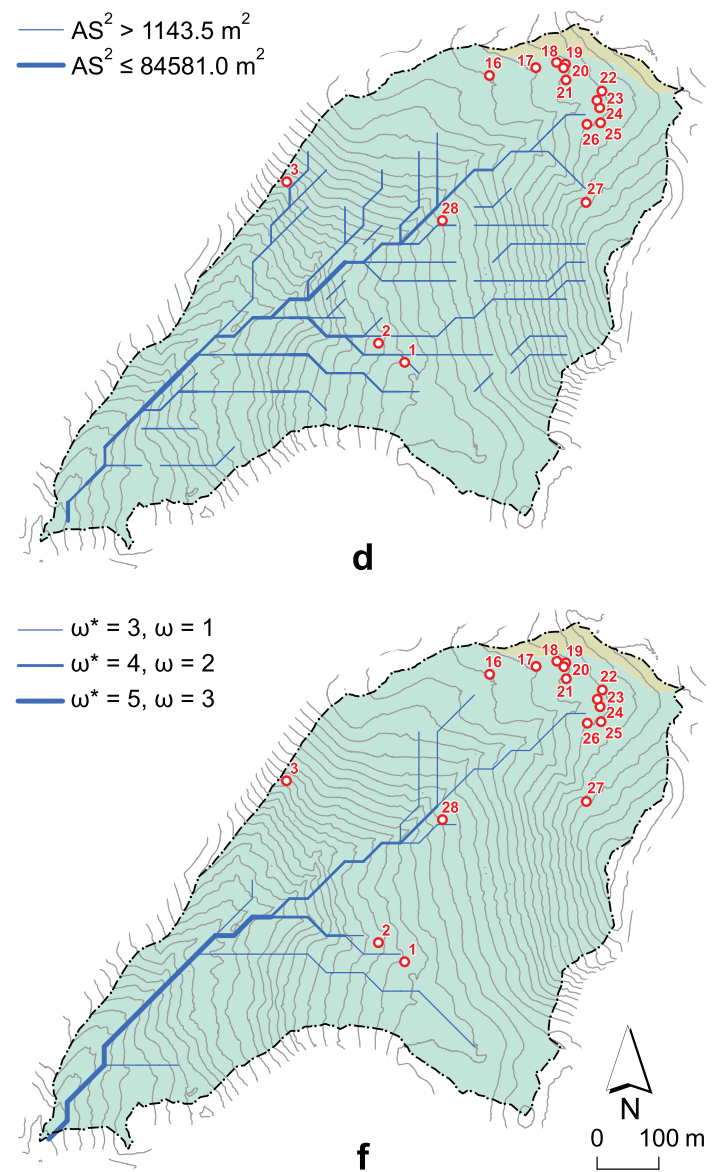

Figure 3. Channel networks obtained from (a, c, e) 3 and (b, d, f) $30 \mathrm{~m}$ gridded elevation data of DB1 by using the threshold values for channel initiation given by the relationships reported in Table 1, namely, $A_{t}=3481.3 \mathrm{~m}^{2},\left(A S^{2}\right)_{t}=510.1 \mathrm{~m}^{2}$, and $\omega_{t}^{*}=4$ for $h=3 \mathrm{~m}$ and $A_{t}=9553.5 \mathrm{~m}^{2},\left(A S^{2}\right)_{t}=$ $1143.5 \mathrm{~m}^{2}$, and $\omega_{t}^{*}=2$ for $h=30 \mathrm{~m}$. Line width varies with $\log (A)$ (Figures $3 \mathrm{a}$ and $\left.3 \mathrm{~b}\right), \log \left(A S^{2}\right)($ Figures $3 \mathrm{c}$ and $3 \mathrm{~d}$ ), or $\omega$ (Figures $3 \mathrm{e}$ and $3 \mathrm{f}$ ). Contour interval is $10 \mathrm{~m}$. 

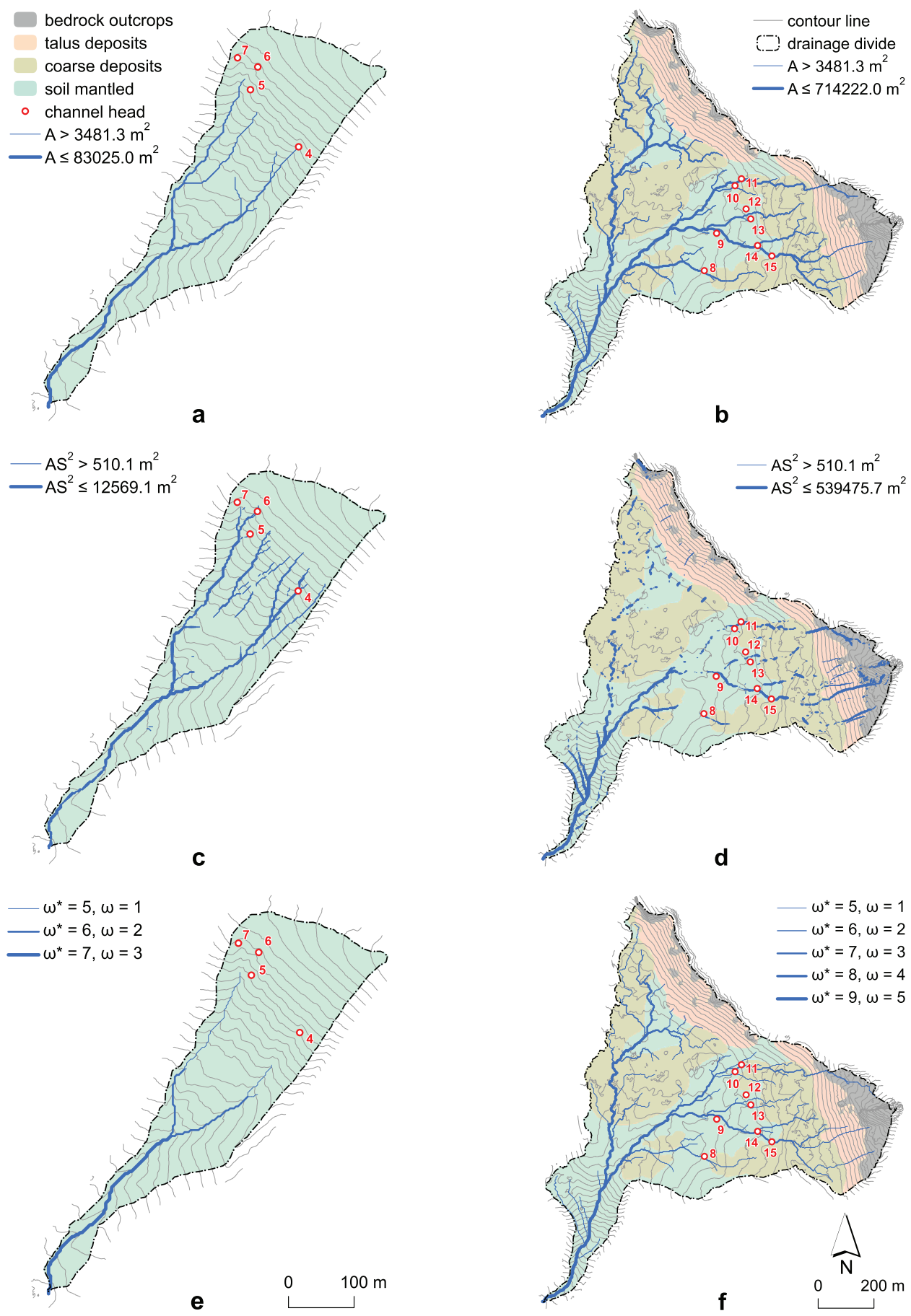

Figure 4. Channel networks obtained from $3 \mathrm{~m}$ gridded elevation data of (a, c, and e) DB2 and (b, d, and f) DB3 by using the threshold values for channel initiation given by the relationships reported in Table 1, namely, $A_{t}=3481.3 \mathrm{~m}^{2},\left(A S^{2}\right)_{t}=510.1 \mathrm{~m}^{2}$, and $\omega_{t}^{*}=4$. Line width varies with $\log (A)$ (Figures $4 \mathrm{a}$ and $4 \mathrm{~b}), \log \left(A S^{2}\right)$ (Figures $4 \mathrm{c}$ and $\left.4 \mathrm{~d}\right)$, or $\omega$ (Figures $4 \mathrm{e}$ and $4 \mathrm{f}$ ). Contour interval is $10 \mathrm{~m}$.

Strahler classification of surface flow paths extracted directly from gridded elevation data and pruning the exterior links with orders less than or equal to $\omega_{t}^{*}$, with $\omega_{t}^{*}=4$ for $h=3 \mathrm{~m}$ (Figure 3e) and $\omega_{t}^{*}=2$ for $h=30 \mathrm{~m}$ (Figure 3f). The channel networks extracted using the thresholds $A_{t}$ and $\left(A S^{2}\right)_{t}$ (Figures $\left.3 \mathrm{a}-3 \mathrm{~d}\right)$ reproduce the observed channels but also indicate many occurrences of channels in locations where channels are not observed (Figure 1). Fig- ure 4 shows the channel heads obtained from the elevation data of DB2 (Figures 4a, 4c, and 4e) and DB3 (Figures 4b, $4 \mathrm{~d}$, and $4 \mathrm{f}$ ) at the resolution of $3 \mathrm{~m}$, using the values of $A_{t}$ (Figures $4 \mathrm{a}$ and $4 \mathrm{~b}),\left(A S^{2}\right)_{t}$ (Figures $4 \mathrm{c}$ and $\left.4 \mathrm{~d}\right)$, and $\omega_{t}^{*}$ (Figures $4 \mathrm{e}$ and $4 \mathrm{f}$ ) given by the relationships reported in Figure 2 and Table 1, namely, $A_{t}=3481.3 \mathrm{~m}^{2},\left(A S^{2}\right)_{t}=$ $510.1 \mathrm{~m}^{2}$, and $\omega_{t}^{*}=4$. While the results obtained for DB2 are satisfactorily consistent with those obtained for DB1, 
the channel networks predicted for DB3 are generally much more developed than can be observed in the field (Figure 1). The inability of the examined methods to reproduce the channel networks observed in DB3 is discussed in section 6 .

\section{Analysis of Quality}

[18] The quality of methods for the prediction of channel heads is evaluated for all considered drainage basins and grid cell sizes by computing two indexes of reliability and sensitivity. These two indexes are based on the binary classification of predictions expressed in terms of true positives (TP), false positives (FP), and false negatives (FN). As sketched in Figure 5, circles having a fixed radius are drawn around each observed channel head to define reasonable neighborhoods for them. A radius equal to the largest grid cell size considered in this study, namely, $30 \mathrm{~m}$, is selected. $\mathrm{TP}$ are considered to be those predictions that fall within at least one of the circles drawn around the observed channel heads. FP are considered to be those predictions that do not fall within any of the circles drawn around the observed channel heads. FN are represented in this study by those circles drawn around the observed channel heads that do not contain any predictions. The reliability of a method, when applied to a given drainage basin, is defined as

$$
r=\frac{\sum \mathbf{T P}}{\sum \mathbf{T P}+\sum \mathbf{F P}},
$$

where $\sum \mathbf{T P}$ and $\sum \mathbf{F P}$ are the total numbers of true and false positives, respectively. This index provides a measure of the method's ability to not predict channel heads where

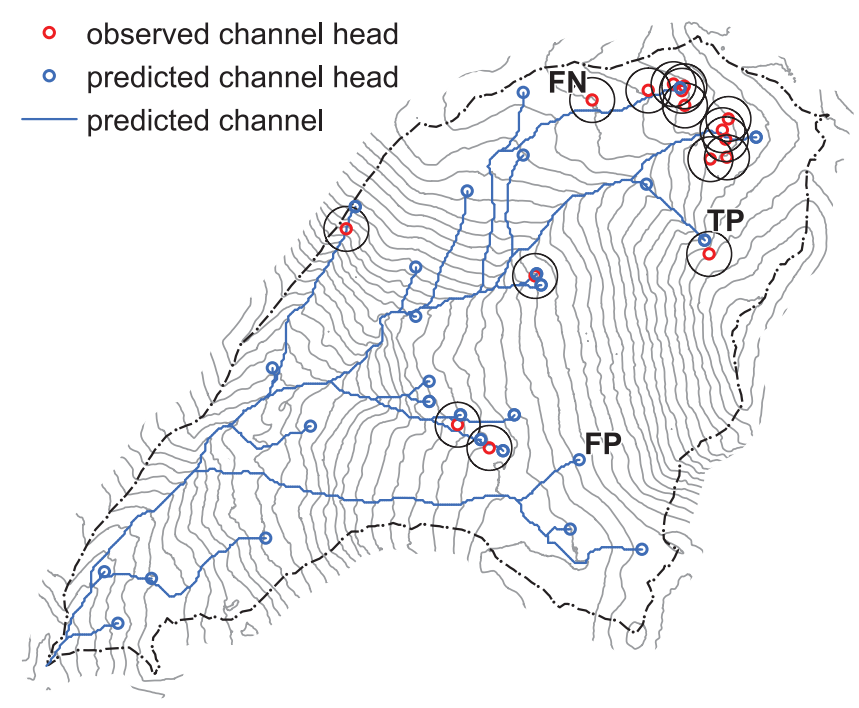

Figure 5. Sketch of the methodology used to determine a binary classification of predicted channel heads. Circles having a fixed radius are drawn around all the observed channel heads. True positives (example labeled TP) are those predictions falling within at least one of these circles. False positives (example labeled FP) are those predictions that do not fall in any of these circles. False negatives (example labeled FN) are represented in this study by circles that do not contain any predicted channel heads. channel heads are not observed, that is, the ability to not generate false positives. The sensitivity of a method, when applied to a given drainage basin, is defined as

$$
s=\frac{\sum \mathbf{T P}}{\sum \mathbf{T P}+\sum \mathbf{F N}},
$$

where $\sum$ TP and $\sum \mathbf{F N}$ are the total numbers of true positives and false negatives, respectively. This index provides a measure of the method's ability to predict all observed channel heads, that is, the ability to not allow for false negatives.

[19] A good method is reliable and sensitive. The variations of $r$ and $s$ with the grid cell size $h$, obtained by applying the considered methods to DB1, DB2, and DB3, are reported in Figure 6. The obtained values of $r$ and $s$ are clearly affected by the radius selected to define the neighborhoods of the observed channel heads. The results reported in Figure 6 (obtained by using a radius of $30 \mathrm{~m}$ ) are, however, representative of the general patterns displayed by the variations of $r$ and $s$ with $h$. It is specified here that other indexes requiring the evaluation of true negatives, such as those used by Grabs et al. [2009], are not suitable for the analysis reported in the present study because a definition of true negatives that is essentially independent of grid cell size cannot be provided.

\section{Discussion}

[20] The study area shown in Figure 1 represents a difficult case for the prediction of channel heads because it is composed of complex calcareous rocks forming high cliffs and various kinds of colluvial and alluvial deposits. In these geomorphological settings, channel heads are observed to occur by surface erosion in response to water and sediment loads released by upstream areas (channel heads $1-7$ and $25-28$ in Figure 1), as well as by groundwater seeping upward at the base of rock cliffs where highly permeable fractured rocks interface with less permeable sediments (channel heads 8-24 in Figure 1). In order to evaluate the capabilities of simple predictive models based on terrain attributes such as drainage area, local slope, and Strahler classification of surface flow paths to identify and predict channel heads, no distinction between channel heads formed by surface runoff and by groundwater seeping upward is made a priori in the analysis reported in this paper. In addition, while it is acknowledged that different surface runoff production mechanisms (infiltration excess, saturation excess, and subsurface stormflow returning upward) may coexist during high-frequency rainfall events, infiltration excess is considered to be the dominant surface runoff production mechanism during the extreme rainfall events that determine the formation of channel heads.

[21] The plots reported in Figure 2 display the variations of threshold variables for channel initiation $\left(A_{t},\left(A S^{2}\right)_{t}\right.$, and $\left.\omega_{t}^{*}\right)$ with grid cell size $(h)$. For each grid cell size $h$, mean and standard deviation of the threshold variables associated with the 16 channel heads observed in DB1 are represented in the plots by data points and uncertainty bars, respectively, the latter having lengths equal to twice the standard deviations. Standard deviations and related uncertainty bars provide a measure of the uncertainty with which a unique 

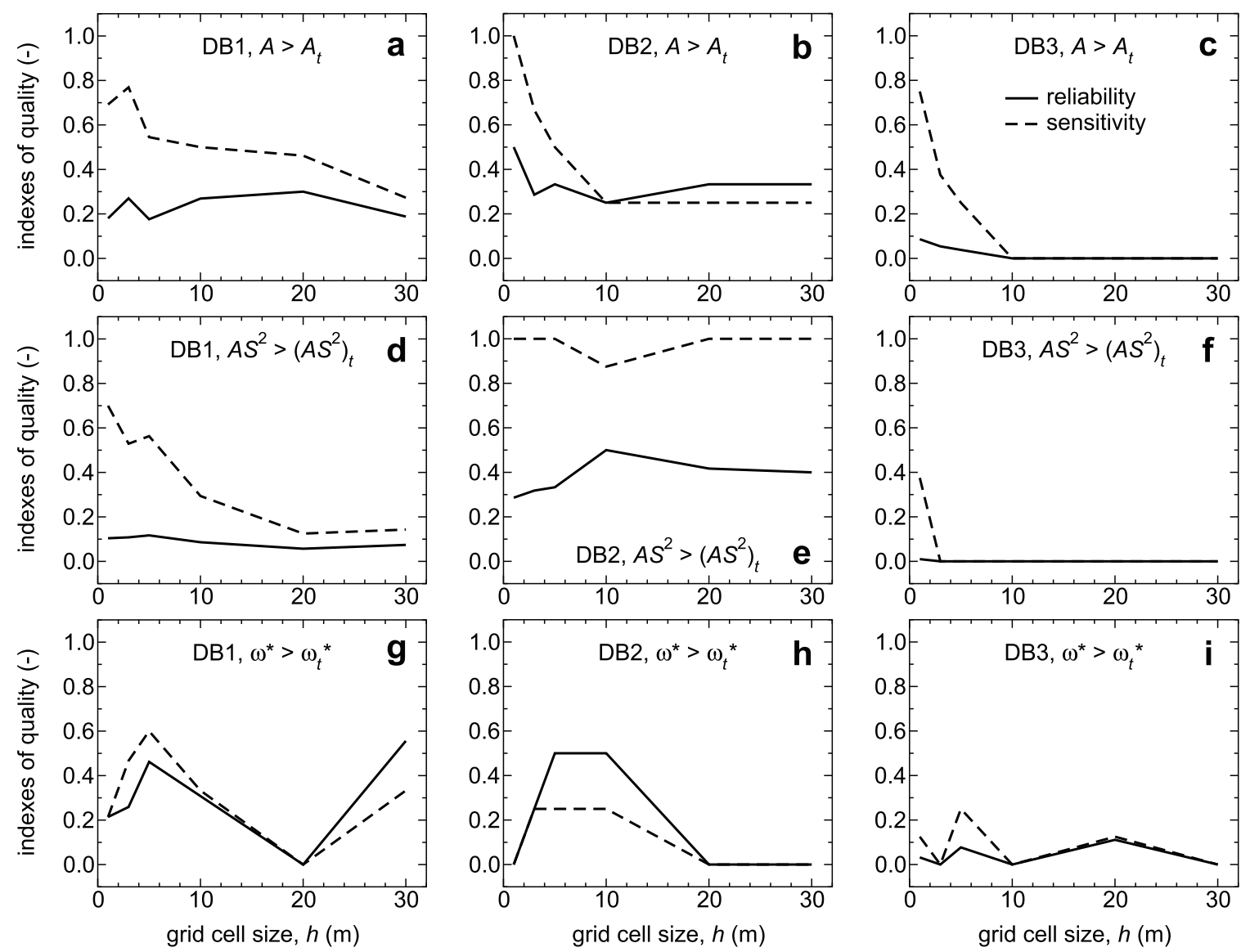

Figure 6. Indexes of quality representing the reliability, as given by equation (3), and the sensitivity, as given by equation (4), of predictive methods based on $(\mathrm{a}-\mathrm{c})$ drainage area $A,(\mathrm{~d}-\mathrm{f})$ area-slope function $A S^{2}$, and $(\mathrm{g}-\mathrm{i})$ Strahler order $\omega^{*}$ in DB1, DB2, and DB3.

value of a threshold variable can be determined and used to reproduce channel heads across DB1. The uncertainty in the determination of $A_{t}$ is found to increase as $h$ increases and to display large values for $h \geq 10 \mathrm{~m}$ (Figure $2 \mathrm{a}$ ). The uncertainty in the determination of $\left(A S^{2}\right)_{t}$ is found to display the highest values for $h=1 \mathrm{~m}$ because of the high variability of local slope at that grid resolution and for $h \geq$ $20 \mathrm{~m}$ because of the increase of uncertainty in $A$ observed when $h$ increases (Figure 2b). The uncertainty in the determination of $\omega_{t}^{*}$ is relatively smaller than that found for $A_{t}$ and $\left(A S^{2}\right)_{t}$, and it does not vary significantly with grid cell size $h$ (Figure 2c). It is remarked here that uncertainty bands reported in Figure 2 indicate the dispersion of threshold values associated with observed channel heads and provide a measure of the methods' sensitivity as given by equation (4). They do not, however, provide any measure of the methods' reliability given by equation (3).

[22] Mean values of $A_{t}$ and $\left(A S^{2}\right)_{t}$ are found to increase with $h$ (Figures $2 \mathrm{a}$ and $2 \mathrm{~b}$ ). These increases are likely to be connected to the fact that larger areas are clearly drained by larger cells associated with the observed channel heads. By considering the relationship $A_{t} / h=2806.61 / h+224.90$ derived from the first relationship reported in Table 1, it can, however, be noted that the ratio $A_{t} / h$ is not constant; rather, it decreases with $h$, from $3031.5 \mathrm{~m}$ for $h=1 \mathrm{~m}$ to $318.5 \mathrm{~m}$ for $h=30 \mathrm{~m}$. It may, therefore, be concluded that the area drained by the grid cells associated with channel head locations increases with the cell size $h$ in an unpredictable manner, certainly not at a constant rate, depending on terrain morphology. The weaker increase of $\left(A S^{2}\right)_{t}$ with $h$ (line slope equal to $23.46 \mathrm{~m}$ in Table 1 ) with respect to the increase of $A_{t}$ with $h$ (line slope equal to $224.90 \mathrm{~m}$ in Table 1) is likely to be connected to the decrease of the local slope $S$ computed as $h$ increases. Simple linear relationships are found to reproduce satisfactorily the variations of $A_{t}$ and $\left(A S^{2}\right)_{t}$ with $h$, providing coefficients of determination $R^{2}$ equal to 0.924 and 0.956 , respectively (Figures $2 \mathrm{a}$ and $2 \mathrm{~b}$ and Table 1). Mean values of $\omega_{t}^{*}$, associated with the channel heads observed in DB1, are found to decrease with $h$ (Figure 2c). This decrease is likely to be connected to the decrease of the degree of branching in the network formed by surface flow paths as grid cell size $h$ increases. A simple power function relationship is found to reproduce quite well the variation of $\omega_{t}^{*}$ with $h$, providing a coefficient of determination $R^{2}$ (computed by using variables transformed logarithmically) equal to 0.994 (Figures $2 \mathrm{c}$ and Table 1).

[23] Satisfactory predictions of channel heads in both DB1 and DB2 are obtained by computing the Strahler classification of surface flow paths and pruning the exterior links (Figures 3e, 3f, and 4e). The comparison between channel networks of DB1 obtained from 3 (Figure 3e) and 
$30 \mathrm{~m}$ (Figure 3f) gridded elevation data reveals that although high-resolution data provide more accurate predictions of surface flow paths, channel heads can be predicted reasonably well by also using low-resolution data, provided that the threshold $\omega_{t}^{*}$ is selected in accordance with the scaling relationship reported in Figure $2 \mathrm{c}$ and Table 1 , namely, $\omega_{t}^{*}=5.869 h^{-0.282}$, which gives $\omega_{t}^{*}=4$ for $h=3 \mathrm{~m}$ and $\omega_{t}^{*}=2$ for $h=30 \mathrm{~m}$. The satisfactory prediction of the channel heads in DB2 provides a validation of the considered methods since the channel heads observed in DB2 are not used for determining the variation of $\omega_{t}^{*}$ with $h$ reported in Figure $2 \mathrm{c}$ and Table 1. It is also stressed that reliable methods for the prediction of channel heads are those that reproduce channel heads observed in the field (true positive) and do not indicate the occurrence of channel heads that are not observed in the field (false positive). Under this perspective, the methods based on threshold values of $A$ and $A S^{2}$ are found to provide less reliable predictions of channel across DB1 and DB2 (Figures $3 \mathrm{a}-3 \mathrm{~d}, 4 \mathrm{a}$, and $4 \mathrm{c})$.

[24] The poorer predictive capabilities of methods based on the thresholds $A_{t}$ and $\left(A S^{2}\right)_{t}$ over that based on the threshold $\omega_{t}^{*}$ are likely related to two factors. First, it may be noted that the drainage area $A$ is an indicator of the amount of water and sediments released to a given location, but it clearly does not incorporate the factors connected to the shape of the drainage basin. The Strahler order $\omega^{*}$, instead, incorporates these factors since it generally increases with the size of the drainage basin, and for a fixed size, it is larger in drainage basins with the higher Horton's [1932] form factor, the latter being defined as the ratio of the area of the drainage basin and square of drainage basin length. Among drainage basins having a fixed area $A$, those displaying a higher Strahler order and form factor are likely to have a smaller time of concentration $t_{c}$ and thus to release a higher peak flow discharge $Q_{T}$ with return period $T$. This can be explained by considering the simple rational formula

$$
Q_{T}=\phi i_{T}\left(t_{c}\right) A
$$

where $\phi$ is the runoff coefficient of the drainage basin and $i_{T}\left(t_{c}\right)$ is the average intensity of the rainfall event with duration equal to the time of concentration $t_{c}$ and return period $T$. Since $i_{T}\left(t_{c}\right)$ increases as $t_{c}$ decreases, higher $Q_{T}$ is produced by drainage basins with lower $t_{c}$. In addition, convective cells producing extreme rainfall events in short durations, comparable with the times of concentration of drainage basins contributing to channel heads, normally display a small extension in space and are therefore more likely to affect entirely drainage basins with high form factors. Hence, the higher flow discharges released by drainage basins having area $A$ are likely to occur for those drainage basins having the smallest times of concentration, a higher form factor, and higher surface flow path Strahler order $\omega_{t}^{*}$. It is stressed here that this discussion is based on the assumption that infiltration excess is the dominant surface runoff production mechanism for extreme rainfall events determining the formation of channel heads.

[25] The second factor is the high variability of local slope $S$. While the threshold $\left(A S^{2}\right)_{t}$ has been theoretically justified and extensively verified in the field [e.g., Montgomery and Dietrich, 1989], its applicability to the auto- mated identification of channel heads suffers from the limitations connected to the use of the drainage area mentioned above and to the high variability of computed values of the local slope $S$. The use of more robust estimates of the slope $S$ compared to those obtained from the local analysis of terrain data is an issue that needs to be considered in future investigations. Although a more comprehensive validation of the assumptions made may be carried out, the discussion reported here provides a reasonable explanation for the reason why numerous channels are predicted using the thresholds $A_{t}$ and $\left(A S^{2}\right)_{t}$ in areas of DB1 and DB2, where long, nearly parallel flow paths occur, while these channels are not predicted using the threshold $\omega^{*}$. In these cases, the increase in the drainage area $A$ does not imply an increase in surface flow path order $\omega^{*}$ and does not represent the propensity of the area to release water and sediments.

[26] Inaccurate predictions of channel networks are obtained in DB3 (Figures 4b, 4d, and 4f). All methods under consideration overestimate the extension of the channel network. The method based on the threshold $\left(A S^{2}\right)_{t}$ appears to provide the best results since it does not reproduce a clear channel network in the NW part of the drainage basin, where channels are not observed to occur. It is, however, specified here that only the drainage system elements for which $A S^{2}>510.1 \mathrm{~m}^{2}$ are drawn in Figure 4d, and an extended channel network could be shown in Figure 4d, as well as in Figures 3c, 3d, and 4c, by representing the full extension of channels originating in the uppermost locations where the threshold $\left(A S^{2}\right)_{t}$ is exceeded. More importantly, as highlighted by the geological characterization reported in Figures 1 and 4d, a strong control of geology on the formation of channel heads is exercised in DB3, implying that channel heads observed in that drainage basin are essentially produced by groundwater seeping upward and not only by surface runoff. Such processes affecting the formation of channel heads can hardly be reproduced by considering simple geomorphometric variables such as $A, S$, and $\omega^{*}$ and need to be investigated in future works by considering detailed hydrologic models of surface-subsurface flow interaction, such as that developed by Camporese et al. [2010].

[27] The analysis of quality shown in Figures 5 and 6 provides a view of the methods' reliability $r$ and sensitivity $s$ as evaluated over the three drainage basins considered (DB1, DB2, and DB3) and the grid cell sizes considered (1, $3,5,10,20$, and $30 \mathrm{~m}$ ). One can note that the values of $r$ and $s$ given by equations (3) and (4), respectively, display rather low values even when the related channel networks are visually satisfactory. For instance, for the channel network shown in Figure 3e, $r=0.259$ and $s=0.467$ (Figure $6 \mathrm{~g}$ ). In most of the cases, the sensitivity $s$ is found to display higher values compared to the reliability $r$, indicating that the considered methods generate more channel heads with respect to those that can actually be observed in the field. This is an issue that needs to be acknowledged in drainage basin hydrology. Because channel flow velocity is normally 1 order of magnitude higher than overland flow velocity, an overestimation of the channel network extension implies an underestimation of the time of concentration and, as given, for instance, by equation (5), an overestimation of the peak discharge released. The reliability of methods is found to vary significantly with the considered drainage basin. In Figure 6 , the values of $r$ obtained for DB1 and DB2 are 
greater than those obtained for DB3 (e.g., Figures $6 g-6 i$ ). The results shown in Figure 6 do not seem to support the use of one method over the others. It may only be observed that the method based on the Strahler classification provides the best results for certain drainage basins and grid cell sizes, but the other two simpler methods provide smoother variations of $r$ and $s$ with the grid cell size and may therefore be considered to be more robust in that respect.

\section{Conclusions}

[28] The ability of threshold conditions for channel initiation to identify and predict observed channel heads was evaluated (Figure 1). The threshold conditions considered were defined in terms of (1) drainage area $A_{t},(2)$ area-slope function $\left(A S^{2}\right)_{t}$, and (3) Strahler order of surface flow paths extracted from gridded elevation data $\omega_{t}^{*}$. By computing threshold values from field observations and gridded elevation data, it was found that (1) $A_{t},\left(A S^{2}\right)_{t}$, and $\omega_{t}^{*}$ are all significantly dependent on grid cell size, (2) uncertainty in the determination of $\omega_{t}^{*}$ is significantly smaller than that affecting the determination of $A_{t}$ and $\left(A S^{2}\right)_{t}$, and (3) $\omega_{t}^{*}$ follows quite well a power function relationship of grid cell size (Figure 2 and Table 1). It was, however, shown that predictive methods based on well-identified threshold conditions may be expected to be sensitive but not necessarily reliable (equations (3) and (4), Figure 5). In fact, the considered methods were all found to display variable reliability and sensitivity over drainage basins having different morphology and grid cell sizes, with a general tendency to predict more channel heads than can be observed in the field (Figures 3, 4 , and 6). In addition, the case of DB3 revealed that the considered threshold conditions are unable to predict accurately the observed channel heads in areas where geology and groundwater seeping upward exercise important controls on channel initiation (Figures 1, 4, and 6). The case study presented in this paper provides an in-depth, yet limited, assessment of our capabilities to predict channel heads across a complex area. Although acceptable predictions are obtained where channel heads are formed essentially by surface runoff, more comprehensive methods incorporating the surfacesubsurface flow interaction appear to be needed to advance our scientific understanding of the formation of channel heads and to improve the reliability with which the channel network is represented in distributed catchment models.

[29] Acknowledgments. This study was carried out under the research programs PRIN 2005 (grant 2005072101) and PRIN 2008 (grant 2008A7EBA3) funded by the Italian Ministry of Education, University, and Research. Part of the resources used in this work was provided by the Interdepartmental Research Center for Cartography, Photogrammetry, Remote Sensing and GIS at the University of Padova (CIRGEO). The authors are grateful to the Associate Editor and the anonymous reviewers for comments that led to improvements in the manuscript.

\section{References}

Borga, M., G. Dalla Fontana, and F. Cazorzi (2002), Analysis of topographic and climatic control on rainfall-triggered shallow landsliding using a quasi-dynamic wetness index, J. Hydrol., 268(1-4), 56-71, doi:10.1016/S0022-1694(02)00118-X.

Camporese, M., C. Paniconi, M. Putti, and S. Orlandini (2010), Surfacesubsurface flow modeling with path-based runoff routing, boundary condition-based coupling, and assimilation of multisource observation data, Water Resour. Res., 46, W02512, doi:10.1029/2008WR007536.
Cavalli, M., P. Tarolli, L. Marchi, and G. Dalla Fontana (2008), The effectiveness of airborne lidar data in the recognition of channel bed morphology, Catena, 73(3), 249-260, doi:10.1016/j.catena.2007.11.001.

Dietrich, W. E., and T. Dunne (1993), The channel head, in Channel Network Hydrology, edited by K. Beven and M. J. Kirkby, pp. 175-219, John Wiley, New York.

Dietrich, W. E., C. J. Wilson, D. R. Montgomery, and J. McKean (1993), Analysis of erosion thresholds, channel networks, and landscape morphology using a digital terrain model, J. Geol., 101(2), 259-278.

Dunne, T., and L. B. Leopold (1978), Water in Environmental Planning, 818 pp., W. H. Freeman, New York.

Grabs, T., J. Seibert, K. Bishop, and H. Laudon (2009), Modeling spatial patterns of saturated areas: A comparison of the topographic wetness index and a dynamic distributed model, J. Hydrol., 373(1-2), 15-23, doi:10.1016/j.jhydrol.2009.03.031.

Hancock, G. R., and K. G. Evans (2005), Channel head location and characteristics using digital elevation models, Earth Surf. Process. Landforms, 31(7), 809-824, doi:10.1002/esp.1285.

Horton, R. E. (1932), Drainage basin characteristics, Eos Trans. AGU, 13, $350-361$.

Horton, R. E. (1945), Erosional development of streams and their drainage basins: Hydrophysical approach to quantitative morphology, Geol. Soc. Am. Bull., 56(3), 275-370.

Howard, A. D. (1994), A detachment-limited model of drainage basin evolution, Water Resour. Res., 30(7), 2261-2285.

Ijjasz-Vasquez, E. J., and R. L. Bras (1995), Scaling regimes of local slope versus contributing area in digital elevation models, Geomorphology, 12(4), 299-311, doi:10.1016/0169-555X(95)00012-T.

Imaizumi, F., T. Hattanji, and Y. S. Hayakawa (2010), Channel initiation by surface and subsurface flows in a steep catchment of the Akaishi Mountains, Japan, Geomorphology, 115(1-2), 32-42, doi:10.1016/ j.geomorph.2009.09.026.

Istanbulluoglu, E., D. G. Tarboton, R. T. Pack, and C. Luce (2002), A probabilistic approach for channel initiation, Water Resour. Res., 38(12), 1325, doi:10.1029/2001WR000782.

Kirkby, M. J. (1993), Long term interactions between networks and hillslopes, in Channel Network Hydrology, edited by K. Beven and M. J. Kirkby, pp. 255-293, John Wiley, New York.

Kirkby, M. J., L. J. Bull, J. Poesenc, J. Nachtergaelec, and L. Vandekerckhove (2003), Observed and modelled distributions of channel and gully heads-With examples from SE Spain and Belgium, Catena, 50(2-4), 415-434, doi:10.1016/S0341-8162(02)00128-5.

Lashermes, B., E. Foufoula-Georgiou, and W. E. Dietrich (2007), Channel network extraction from high resolution topography using wavelets, Geophys. Res. Lett., 34, L23S04, doi:10.1029/2007GL031140.

Leopold, L. B. (1994), A View of the River, Harvard Univ. Press, Cambridge, Mass.

Leopold, L. B., M. G. Wolman, and J. P. Miller (1964), Fluvial Processes in Geomorphology, W. H. Freeman, San Francisco, Calif.

Martz, L. W., and J. Garbrecht (1995), Automated recognition of valley lines and drainage networks from grid digital elevation models: A review and a new method-Comment, J. Hydrol., 167(1-4), 393-396.

Maxwell, J. C. (1870), On hills and dales, London Edinburgh Dublin Philos. Mag. J. Sci., 4/40(269), 421-425.

McNamara, J. P., A. D. Ziegler, S. H. Wood, and J. B. Vogler (2006), Channel head locations with respect to geomorphologic thresholds derived from a digital elevation model: A case study in northern Thailand, For. Ecol. Manage., 224(7), 147-156.

Montgomery, D. R., and J. M. Buffington (1997), Channel-reach morphology in mountain drainage basins, Geol. Soc. Am. Bull., 109(5), 596-611.

Montgomery, D. R., and W. E. Dietrich (1988), Where do channels begin?, Nature, 336(6196), 232-234.

Montgomery, D. R., and W. E. Dietrich (1989), Source areas, drainage density and channel initiation, Water Resour. Res., 25(8), 1907-1918.

Montgomery, D. R., and W. E. Dietrich (1992), Channel initiation and the problem of landscape scale, Science, 255(5046), 826-830.

Montgomery, D. R., and E. Foufoula-Georgiou (1993), Channel network source representation using digital elevation models, Water Resour. Res., 29(12), 3925-3934

Moretti, G., and S. Orlandini (2008), Automatic delineation of drainage basins from contour elevation data using skeleton construction techniques, Water Resour. Res., 44, W05403, doi:10.1029/2007WR006309.

O'Callaghan, J., and D. M. Mark (1984), The extraction of drainage networks from digital elevation data, Comput. Vision Graphics Image Process., 28(3), 323-344. 
Orlandini, S., and G. Moretti (2009a), Determination of surface flow paths from gridded elevation data, Water Resour. Res., 45, W03417, doi:10.1029/2008WR007099.

Orlandini, S., and G. Moretti (2009b), Comment on "Global search algorithm for nondispersive flow path extraction" by Kyungrock Paik, $J$. Geophys. Res., 114, F04004, doi:10.1029/2008JF001193.

Orlandini, S., and R. Rosso (1998), Parameterization of stream channel geometry in the distributed modeling of catchment dynamics, Water Resour. Res., 34(8), 1971-1985.

Orlandini, S., G. Moretti, M. Franchini, B. Aldighieri, and B. Testa (2003), Path-based methods for the determination of nondispersive drainage directions in grid-based digital elevation models, Water Resour. Res. 39(6), 1144, doi:10.1029/2002WR001639.

Orlandini, S., C. Boaretti, V. Guidi, and G. Sfondrini (2006), Field determination of the spatial variation of resistance to flow along a steep Alpine stream, Hydrol. Processes, 20(18), 3897-3913, doi:10.1002/hyp.6163.

Passalacqua, P., T. D. Trung, E. Foufoula-Georgiou, G. Sapiro, and W. E. Dietrich (2010a), A geometric framework for channel network extraction from lidar: Nonlinear diffusion and geodesic paths, J. Geophys. Res., 115, F01002, doi:10.1029/2009JF001254.

Passalacqua, P., P. Tarolli, and E. Foufoula-Georgiou (2010b), Testing space-scale methodologies for automatic geomorphic feature extraction from lidar in a complex mountainous landscape, Water Resour. Res., 46, W11535, doi:10.1029/2009WR008812.

Peckham, S. D. (1995), Self-similarity in the three-dimensional geometry and dynamics of large river basins, Ph.D. thesis, Univ. of Colo., Boulder.

Pilotti, M., C. Gandolfi, and G. B. Bischetti (1996), Identification and analysis of natural channel networks from digital elevation models, Earth Surf. Processes Landforms, 21(11), 1007-1020.

Pirotti, F., and P. Tarolli (2010), Suitability of lidar point density and derived landform curvature maps for channel network extraction, Hydrol. Processes, 24(9), 1187-1197, doi:10.1002/hyp.7582.

Quinn, P., K. Beven, P. Chevallier, and O. Planchon (1991), The prediction of hillslope flow paths for distributed hydrological modeling using digital terrain models, Hydrol. Processes, 5(1), 59-80.

Seibert, J., and B. L. McGlynn (2007), A new triangular multiple flow direction algorithm for computing upslope areas from gridded digital elevation models, Water Resour. Res., 43, W04501, doi:10.1029/2006WR005128.
Sibson, R. (1981), A brief description of natural neighbor interpolation, in Interpreting Multivariate Data, edited by V. Barnett, pp. 21-36, John Wiley, Chichester, U. K.

Strahler, A. N. (1952), Hypsometric (area-altitude) analysis of erosional topology, Geol. Soc. Am. Bull., 63(11), 1117-1142.

Strahler, A. N. (1957), Quantitative analysis of watershed geomorphology, Eos Trans. $A G U, 8(6), 913-920$

Tarboton, D. G. (1997), A new method for the determination of flow directions and upslope areas in grid digital elevation models, Water Resour. Res., 33(2), 309-319.

Tarboton, D. G., R. L. Bras, and I. Rodriguez-Iturbe (1988), The fractal nature of river networks, Water Resour. Res., 24(8), 1317-1322.

Tarolli, P., and G. Dalla Fontana (2009), Hillslope-to-valley transition morphology: New opportunities from high resolution DTMs, Geomorphology, 113(1-2), 47-56, doi:10.1016/j.geomorph.2009.02.006.

Tarolli, P., M. Borga, and G. Dalla Fontana (2008), Analyzing the influence of upslope bedrock outcrops on shallow landsliding, Geomorphology, 93(3-4), 186-200, doi:10.1016/j.geomorph.2007.02.017.

Taylor, J. R. (1997), An Introduction to Error Analysis: The Study of Uncertainties in Physical Measurements, Univ. Sci. Books, Sausalito, Calif.

Tribe, A. (1992), Automated recognition of valley lines and drainage networks from grid digital elevation models: A review and a new method, $J$. Hydrol., 139(1-4), 263-293.

Vianello, A., and V. D'Agostino (2007), Bankfull width and morphological units in an alpine stream of the dolomites (northern Italy), Geomorphology, 83(3-4), 266-281, doi:10.1063/1.2825070.

Willgoose, G., R. L. Bras, and I. Rodriguez-Iturbe (1991), A coupled channel network growth and hillslope evolution model: 1. Theory, Water Resour. Res., 27(7), 1671-1684.

G. Dalla Fontana and P. Tarolli, Department of Land and Agroforest Environments, University of Padova, Agripolis, Viale dell'Università 16, I-35020 Padova, Italy. (giancarlo.dallafontana@unipd.it; paolo.tarolli@unipd.it)

G. Moretti and S. Orlandini, Department of Mechanical and Civil Engineering, University of Modena and Reggio Emilia, Via Vignolese 905, I-41125 Modena, Italy. (giovanni.moretti@unimore.it; stefano.orlandini@unimore.it) 